\title{
Reply to "The Missing, the Short, and the Long: Exploring the borderland between psychiatry and
}

\section{$\underline{\text { neurology" }}$}

We thank Dr. Moses for his interest in and generous comments about our article. His comments highlight a critical and inadequately explored aspect of striatal dopaminergic neurotransmission; the nature and roles of long-term plastic changes. Aberrant plasticity of striatal dopaminergic neurotransmission has been explored in the context of treatment induced dyskinesias, but as Dr. Moses points out, there may be other important clinical phenomena involving chronically altered striatal dopaminergic neurotransmission. Hallucinations can be induced, even in normal subjects, via Pavlovian conditioning, a form of reinforcement learning associated with striatal dopaminergic neurotransmission. ${ }^{1}$ Recent functional imaging data suggests striatal involvement in the phenomenon of induced hallucinations, raising the possibility that chronic alterations in striatal dopaminergic neurotransmission associated with Parkinson disease mediate hallucinosis. ${ }^{1}$ Alterations of dopaminergic neurotransmission in nonstriatal circuits may also be involved. Arnulf and colleagues suggested that hallucinations in Parkinson disease are elements of dream activity intruding into wakefulness, a process possibly driven by aberrant dopaminergic modulation of hypothalamic and brainstem circuits controlling sleep, ${ }^{2,3}$ We agree with Dr. Moses that further research in this area may be fruitful.

Roger L. Albin, MD

Neurology Service \& GRECC, VAAAHS

Dept. of Neurology, University of Michigan

Ann Arbor, MI, 48109-2200

\section{Daniel K. Leventhal, MD, PhD}

\section{Neurology Service \& GRECC, VAAAHS}

This is the author manuscript accepted for publication and has undergone full peer review but has not been through the copyediting, typesetting, pagination and proofreading process, which may lead to differences between this version and the Version record. Please cite this article as doi:10.1002/ ana.25033. 
Dept. of Neurology, University of Michigan

Ann Arbor, MI, 48109-2200

Potential Conflicts of Interest: Nothing to report.

Author Contributions: Both authors contributed equally to drafting this reply.

1) Powers AR, Mathys $C$, Corlett PR. Pavlovian conditioning-induced hallucinations result from overweighting of perceptual priors. Science 2017;357:596-600.

2) Arnulf I, Bonnet AM, Damier P, Bejjani BP, Seilhean D, Derenne JP, Agid Y. Hallucinations, REM sleep, and Parkinson's disease: a medical hypothesis. Neurology $2000 ; 55: 281-288$.

3) Leu-Semenescu S, De Cock VC, Le Masson VD, Debs R, Lavault S, Roze E, Vidailhet M, Arnulf I. Hallucinations in narcolepsy with and without cataplexy: contrasts with Parkinson's disease. Sleep Med 2011;12:497-504.

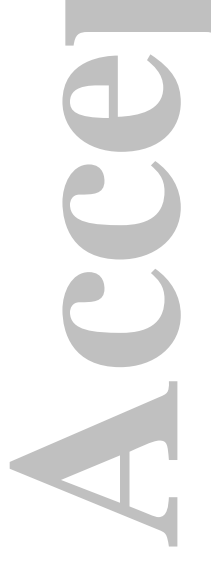

